\title{
Factors affecting discrimination toward people with HIV/AIDS in Sarawak, Malaysia
}

\author{
Md M. Rahman, Aren S. Lemin, Cliffton A. Pangarah \\ Universiti Malaysia Sarawak, Kota Samarahan, Malaysia
}

\begin{abstract}
Introduction: The issue of discrimination is related not only to people living with human immunodeficiency virus (HIV)/acquired immunodeficiency syndrome (AIDS) (PLWH), but also the community around them. The study aimed to determine the perceived level of discrimination toward people with HIV/AIDS among the adult people in Sarawak, Malaysia and also to determine the factors associated with it.

Material and methods: This was a community-based cross-sectional study conducted in rural areas of Sarawak. A total of 900 adults aged 18 years and above were selected by gender-stratified multistage cluster sampling technique. Data were collected by face-to-face interview using interviewer-guided questionnaires. Stepwise multiple linear regression analysis was performed using SPSS version 22.0 to identify the factors associated with HIV/AIDS-related discrimination towards PLWH. A $p$-value less than 0.05 was considered to be statistically significant.

Results: The mean (SD) age for male and female respondents was 41.57 (13.45) and 38.99 (13.09) years respectively. The composite mean score for total discrimination was higher among female (mean $=2.66, \mathrm{SD}=0.6)$ than male (mean $=2.47, \mathrm{SD}=0.6)$ respondents. Domain-wise discrimination of HIV/AIDS found that isolation, verbal discrimination, loss of resources, loss of services and total discrimination were significantly high among the females $(p<0.05)$ compared to males. Stepwise multiple linear regression analysis revealed that ethnicity, religion, knowledge on HIV, an acquaintance of HIV and household income appeared to be potential predictors for discrimination towards peoples living with HIV/AIDS $(p<0.05)$.

Conclusions: HIV/AIDS-related discrimination towards 0 coexisted among the community in Sarawak, and this called for a specific socio-culturally accepted intervention to eliminate the discrimination against people with HIV/AIDS.
\end{abstract}

HIV AIDS Rev 2020; 19, $1: 49-55$ DOI: https://doi.org/10.5114/hivar.2019.85916

Key words: HIV/AIDS, discrimination, HIV/AIDS, Sarawak, Malaysia.

\section{Introduction}

Globally, 36.9 million people were living with human immunodeficiency virus (HIV) at the end of 2017 [1] and the trend is increasing. Various approaches have been taken by the government to combat the HIV/acquired immunodeficiency syndrome (AIDS) epidemic, including the National Strategic Plan on HIV/AIDS, which includes the involvement of multiple agencies such as non-governmental organizations (NGOs), religious leaders, and the community. Despite
Address for correspondence: Prof. Md M. Rahman, Universiti Malaysia Sarawak, 94300 Kota Samarahan, 94300 , Kota Samarahan, Malaysia, phone: +60109745920 , e-mail: rmmizanur@unimas.my
Article history:

Received: 04.06.2018

Received in revised form: 20.12.2018

Accepted: 21.12.2018

Available online: 25.05.2019
International Journal of HIV-Related Problems

HIV \& AIDS

R e v i e w 
the efforts, the number of HIV cases, especially, in Sarawak, is increasing [2]. This might be a one of the reasons for the widespread care and support to people living with HIV/ AIDS co-existing with the stigma and discrimination [3]. HIV/AIDS-related discrimination is an action due to stigma. Discrimination is defined as: "Unfair and unjust treatment (act or omission) of an individual based on his or her real or perceived HIV status" [4].

HIV/AIDS-related discrimination is widely recognized as a barrier to access HIV/AIDS prevention, treatment and care services [5], and this continue to fuel the global AIDS epidemic.

Discrimination against people living with HIV (PLWH) has extensively risen in different cultures and countries, namely, among adult community in Malaysia [6], young people in Tamil Nadu in India [7], Nigeria [8], healthcare providers in urban India [9], and medical students in Selangor Malaysia [10]. Nevertheless, researchers have reported several negative impacts of HIV/AIDS-related discrimination towards PLWH, for example, key obstacles to use HIV services, including delay in receiving care from health centres [11], direct negative effects on mental and emotional health of PLWH [12] and a negative impact on illness behaviour of PLWH such as non-adherence to a medical regime [13]. This is supported by the Ministry of Health, Malaysia [14] report that estimated the number of PLWH who are eligible for treatment as about 37,306. However, only $14,002 \mathrm{HIV} / \mathrm{AIDS}$ patients had received antiretroviral therapy as of December 2011.

From the public health point of view, many studies were done on HIV/AIDS-related discrimination, but not many from a community perspective, especially in Sarawak. The public attitude has not been explored thoroughly. Considering this view, this study aimed to determine factors influencing HIV/AIDS-related discrimination towards people with HIV/AIDS from the community in Sarawak with multi-ethnicity and rich in cultural and religious groups with the possibility of a variety of views about people living with HIV/AIDS.

\section{Material and methods}

\section{Study setting and sampling}

This was a cross-sectional community-based study conducted in Sarawak, Malaysia. A gender-stratified multistage cluster sampling technique was followed to select the respondents. For the sampling procedure, Sarawak State was divided into three regions, namely the Northern, Southern and Central zone. From each zone, a division was randomly selected. From the selected division, two districts were randomly selected. Then 5 villages were randomly selected from each district. Therefore, a total of 30 villages were involved in this study.

For final selection of the respondents, 30 households were selected by stratified systematic random sampling where an adult male and female aged 18 years old and above were selected for every $\mathrm{K}^{\text {th }}$ number of household in the village household list given by the Ketua kampong (village headman). Fifteen household as male and another 15 as female households were selected from 30 households. It was assumed that every household consisted of an adult male or adult female aged 18 years old and above. If there was more than one adult male or adult female one was selected randomly from each household as a sample.

The sample size was calculated with the base proportion of the stigma and discrimination of $60 \%$ (7) with 1.96 standard values for two-tailed tests and $5 \%$ absolute precision. The sample size was further inflated multiplying by design effect 2 and 20\% non-response rate. Thus, the final sample was 885 with rounding to 900 . Thirty respondents were selected from each village.

\section{Data collection instrument}

The data collection instrument was developed after consultation with earlier studies [15-18]. The instrument had several components measuring the HIV/AIDS-related knowledge on HIV/AIDS transmission. It was measured by 17 items questions that were based on two key domains: modes of HIV transmission (10 items) and misconception about HIV transmission (7 items) [17]. The score posed true and false questions that were scored by awarding one point for each correct answer. Then, the second part of questionnaires consisted of media exposure [15] and communication and discussion about HIV/AIDS [16]. These questionnaires consisted of types of communication (mass media or interpersonal communication) and frequency of communication. The third part was HIV/AIDS-related discrimination questionnaires which was adapted from UNAIDS [18] and Ugarte et al. [17]. Respondents responded to 18 items based on a five-point Likert scale ranging from (1) Strongly disagree to (5) Strongly agree. Questions were organized in four domains, viz. (1) isolation, including physical and social exclusion (6 items); (2) verbal stigma (4 items); (3) loss of access to resources (4 items) and (4) loss of access to services (4 items). The highest score of HIV/AIDS-related discrimination would reflect higher HIV/AIDS discrimination toward PLWH.

\section{Data collection procedure}

A pilot test was conducted among 30 respondents. The purpose of this was to test whether the wordings used were clear and whether there was a need to refine the questionnaire further on. The domain-wise Cronbach's $\alpha$ was calculated, and it varied from 0.622 to 0.849 . To maintain the high-quality data, the interviewers were thoroughly trained for one week. There was close supervision of the interviewers during data collection and the questionnaires were thoroughly edited to make sure that relevant questions had been responded to and coded accordingly. Data were collected by face-to-face interview 
at a comfortable time. Three attempts were made to get the sampled respondents.

Ethical approval was obtained from the Medical Ethics Committee of Universiti Malaysia Sarawak (Ref: UNIMAS/ NC-21.02/03-02 Jld.2 (08); 11 February 2016), Clinical Research Centre, and the National Medical Research Register, Ministry of Health (Ref: NMRR-16-192-29374 [IIR]); 31 March 2016. All the respondents were briefed, and written informed consent was obtained before data collection.

\section{Data entry and statistical analysis}

Any missing information was corrected on the same day or next day. Data coding and verification of response was made on the same day immediately after the interview. The cleaned data were entered into a computer using SPSS version 22.0 [19]. For descriptive statistics, frequen- cy, mean, and standard deviation were presented. Initially, domain-wise analysis was done by gender to find the mean differences across the domains. Finally, a stepwise multiple linear regression analysis was done to identify the associated factors for HIV/AIDS-related discrimination towards PLWH. A $p$-value less than 0.05 was considered as statistically significant.

\section{Results}

\section{Socio-demographic characteristics}

Table 1 illustrates the socio-demographic characteristics of the respondents.

The mean age of males was 41.57 years and females 38.99 years, and the mean difference was statistically significant $(p<0.05)$. However, no statistically significant difference was found in ethnicity, religion, living status or family size

Table 1. Gender-wise socio-demographic characteristics

\begin{tabular}{|c|c|c|c|c|c|}
\hline \multirow{2}{*}{ Variables } & \multicolumn{2}{|c|}{ Male $(n=450)$} & \multicolumn{2}{|c|}{ Female $(n=450)$} & \multirow{2}{*}{$p$-value } \\
\hline & Frequency & $\%$ & Frequency & $\%$ & \\
\hline Age (mean, SD) in years & \multicolumn{2}{|c|}{$41.57(13.45)$} & \multicolumn{2}{|c|}{$38.99(13.09)$} & $0.004^{a}$ \\
\hline \multicolumn{6}{|l|}{ Ethnicity } \\
\hline Iban & 77 & 49.0 & 80 & 51.0 & \multirow[t]{4}{*}{$0.988^{b}$} \\
\hline Malay & 200 & 50.6 & 195 & 49.4 & \\
\hline Bidayuh & 73 & 49.7 & 74 & 50.3 & \\
\hline Others $^{d}$ & 100 & 49.8 & 101 & 50.2 & \\
\hline \multicolumn{6}{|l|}{ Religion } \\
\hline Christianity & 106 & 49.3 & 109 & 50.7 & \multirow[t]{3}{*}{$0.705^{b}$} \\
\hline Islam & 313 & 49.8 & 316 & 50.2 & \\
\hline Others $^{\mathrm{e}}$ & 31 & 55.4 & 25 & 44.6 & \\
\hline \multicolumn{6}{|l|}{ Living status } \\
\hline Living with partner & 329 & 73.1 & 325 & 72.2 & \multirow[t]{2}{*}{$0.765^{b}$} \\
\hline Living without partner & 121 & 26.9 & 125 & 27.8 & \\
\hline Median family size & \multicolumn{2}{|c|}{5.0} & \multicolumn{2}{|c|}{5.0} & $0.716^{c}$ \\
\hline \multicolumn{6}{|l|}{ Level of education } \\
\hline No formal education & 76 & 36.2 & 134 & 63.8 & \multirow[t]{4}{*}{$<0.001^{b}$} \\
\hline Primary school & 105 & 55.6 & 84 & 44.4 & \\
\hline Secondary school & 233 & 53.9 & 199 & 46.1 & \\
\hline Tertiary and above & 36 & 52.2 & 33 & 47.8 & \\
\hline \multicolumn{6}{|l|}{ Occupation } \\
\hline Unemployed & 63 & 17.2 & 303 & 82.8 & \multirow[t]{4}{*}{$<0.001^{b}$} \\
\hline Self employed & 187 & 75.1 & 62 & 24.9 & \\
\hline Government job & 61 & 66.3 & 31 & 33.7 & \\
\hline Private job & 139 & 72.0 & 54 & 28.0 & \\
\hline Median $\mathrm{HH}$ income (MYR) & \multicolumn{2}{|c|}{900.0} & \multicolumn{2}{|c|}{800.00} & $0.005^{c}$ \\
\hline
\end{tabular}

${ }^{a} p$-value obtained from independent sample $t$-test; ${ }^{b} p$-value obtained from $\chi^{2}$ test; ${ }^{c} p$-value obtained from Mann-Whitney $U$ test

Others $^{d}$ included Melanau, Cina, Org Ulu; Others ${ }^{e}$ included Buddhism, Hinduism, no religion

${ }^{*} p<0.05 ;{ }^{* *} p<0.01 ;{ }^{* * *} p<0.001$ 
Table 2. HIV/AIDS related characteristics

\begin{tabular}{l|c|c|c}
\hline \multirow{2}{*}{ HIV/AIDS related variables } & Male $(n=450)$ & Female $(n=450)$ & \multirow{2}{*}{$p$-value } \\
\cline { 2 - 3 } & Mean (SD) & Mean (SD) & $<0.001$ \\
\hline Knowledge on HIV/AIDS transmission & $10.49(4.0)$ & $9.42(4.1)$ & 0.933 \\
\hline Sources of HIV information & $2.08(2.9)$ & $2.09(3.1)$ & 0.455 \\
\hline Discussion on HIV/AIDS & $1.58(2.8)$ & $1.44(2.7)$ & 0.731 \\
\hline Media exposure to HIV/AIDS & $2.18(3.9)$ & $2.27(4.1)$ & 0.446 \\
\hline Content of HIV/AIDS information & $5.52(1.1)$ & $5.46(1.2)$ & \\
\hline
\end{tabular}

$p$-value obtained from independent sample t test

${ }^{*} p<0.05 ;{ }^{* *} p<0.01 ;{ }^{* *} p<0.001$

Table 3. Gender-stratified domain-wise discrimination score toward people living with HIV/AIDS

\begin{tabular}{l|c|c|c|c|c}
\hline \multirow{2}{*}{ Domains } & \multirow{2}{*}{ Items } & \multicolumn{2}{|c|}{ Mean (SD) discrimination } & \multirow{2}{*}{ Cronbach's $\alpha$} & \multirow{2}{*}{$\boldsymbol{p}$-value } \\
\cline { 3 - 5 } & & Male $(\boldsymbol{n}=\mathbf{4 5 0})$ & Female $(\boldsymbol{n}=\mathbf{4 5 0})$ & & $<0.001$ \\
\hline Isolation & 6 & $2.56(0.7)$ & $2.77(0.8)$ & 0.816 & $<0.001$ \\
\hline Verbal discrimination & 4 & $2.41(0.7)$ & $2.63(0.7)$ & 0.622 & $<0.001$ \\
\hline Loss of resources & 4 & $2.55(0.7)$ & $2.74(0.8)$ & 0.775 & 0.021 \\
\hline Loss of services & 4 & $2.30(0.9)$ & $2.44(0.9)$ & 0.849 & $<0.001$ \\
\hline Total discrimination & 18 & $2.47(0.6)$ & $2.66(0.6)$ & 0.887 & \\
\hline
\end{tabular}

$p$-value obtained from independent $t$ test

${ }^{*} p<0.05 ;{ }^{* *} p<0.01 ;{ }^{* *} p<0.001$

$(p>0.05)$. A statistically significant difference was found in terms of the level of education, occupation and monthly household income $(p>0.05)$, indicating the proportion of non-formal education and unemployed to be high among the female respondents.

\section{HIV / AIDS-related characteristics}

In this study, there was no statistically significant difference in the source of HIV information, discussion on HIV/ AIDS, media exposure to HIV/AIDS and content of HIV/ AIDS information $(p>0.05)$. Moreover, a statistically significant difference was found in knowledge on HIV/AIDS transmission $(p<0.05)$ and it showed that the knowledge on HIV/AIDS transmission score was higher among male respondents (Table 2).

\section{Domain-wise discrimination score toward people living with HIV / AIDS}

Discrimination consisted of four domains, namely isolation, verbal discrimination, loss of resources and loss of services domains, with a total of 18 items. A statistically significant difference was found between males and females in terms of isolation, verbal discrimination, loss of resources, loss of services and total discrimination $(p<0.05)$, whereby the mean score of each domain of discrimination was higher among females (Table 3).

\section{Factors affecting discrimination towards people living with HIV/AIDS: stepwise multiple linear regression analysis}

A stepwise multiple linear regression analysis was done to identify the potential predictors of discrimination toward peoples living with HIV/AIDS. Initially, all the predictors whether significant or not significant and dependent variables were entered into the model to identify the outliers of the data set based on Mahalanobis distance and Studentized residuals. A total of 48 from female and 42 from male data were removed. The qualitative variables were dummy coded to determine their individual effect in the model. Then stepwise forward multiple linear regression analysis was done to identify the factors. However, before final interpretation, tolerance and variance inflation factors (VIF) were checked for multicollinearity among the independent variables. Variables having potential multicollinearity were removed from the models. Analysis revealed that ethnicity, religion, knowledge on HIV, an acquaintance of HIV and household income appeared to be potential predictors for discrimination towards peoples living with HIV/AIDS.

Among the male respondents, the analysis of the unstandardized regression coefficient $(\beta)$ with $95 \%$ confidence interval, adjusted $R^{2}=0.226, F(6,347)=17.839, p<0.001$ is illustrated in Table 4 . The adjusted $R^{2}$ value of 0.226 indicates that $22.6 \%$ of the variability in HIV/AIDS-related discrimination toward PLWHA was predicted by a number of variables such as ethnic- 
Table 4. Stepwise multiple linear regression analyses for HIV/AIDS-related discrimination towards PLWHA

\begin{tabular}{l|c|c|c|c|c|c}
\hline \multirow{2}{*}{ Variables } & \multicolumn{3}{|c|}{ Male } & \multicolumn{3}{c}{ Female } \\
\cline { 2 - 6 } & $\boldsymbol{N}$ & $95 \% \mathrm{Cl}$ & $\%$ & $\boldsymbol{\beta}$ & $95 \% \mathrm{Cl}$ & $\%$ \\
\hline Iban & $-0.499^{\star * *}$ & $-0.622,-0.372$ & 56.7 & $\mathrm{NI}$ & & \\
\hline Malay & $0.477^{\star *}$ & $0.254,0.700$ & 15.5 & $\mathrm{NI}$ & & \\
\hline Islam & $-0.444^{\star *}$ & $-0.655,-0.233$ & 15.0 & $\mathrm{NI}$ & & \\
\hline Do not know someone who has HIV & $0.635^{*}$ & $0.226,1.044$ & 8.2 & $1.437^{*}$ & $0.471,2.403$ & 8.4 \\
\hline Knowledge of HIV transmission & $\mathrm{NI}$ & & & $-0.030^{* * *}$ & $-0.048,-0.013$ & 23.7 \\
\hline MYR $>1500$ & $\mathrm{NI}$ & & & $-0.324^{* *}$ & $-0.381,-0.034$ & 19.6 \\
\hline MYR $<500$ & $\mathrm{NI}$ & & & $-0.0207^{* *}$ & $-0.381,-0.034$ & 11.4 \\
\hline (Constant) & $2.213^{* * *}$ & $1.719,2.706$ & & $2.521^{* * *}$ & $2.158,2.884$ & \\
\hline Adj $R^{2}$ & 0.226 & & & 0.155 & & \\
\hline$F(\mathrm{df}) ;$ & $17.839(6,347)^{* * *}$ & & & $11.172(5,332)^{* * *}$ & & \\
\hline$n$ & 348 & & & 333 & & \\
\hline
\end{tabular}

$\mathrm{Cl}$ - confidence interval, Adj $\mathrm{R}^{2}-$ Adjusted $\mathrm{R}^{2}, \mathrm{DV}$-discrimination

${ }^{*} p<0.05 ;{ }^{* *} p<0.01 ;{ }^{* * *} p<0.001$

${ }^{*}$ Percentage of contribution

ity, religion and not knowing someone who had HIV $(p<0.05)$. Analysis revealed that Malay ethnicity and did not know someone who had HIV had a significant positive contribution to HIV/AIDS-related discrimination toward PLWHA while Iban ethnicity and Islam negatively influenced HIV/AIDS-related discrimination toward PLWHA. This showed that those male respondents who were of Malay ethnicity ( $\beta=0.477 ; 95 \%$ $\mathrm{CI}=0.254,0.700)$ were more likely to express HIV/AIDS-related discrimination toward PLWHA compared to non-Malay. Similarly, those male respondents who did not know someone who had HIV ( $\beta=0.635$; 95\% CI $=00.226,1.044$ ) were more likely to express HIV/AIDS-related discrimination toward PLWHA compared to those who knew someone who had HIV. However, those of Iban ethnicity $(\beta=-0.499 ; 95 \% \mathrm{CI}=-0.622$, -0.372 ) were less likely to exhibit HIV/AIDS-related discrimination toward PLWHA compared to non-Iban. Similarly, those who had the religion as Islam ( $\beta=-0.444 ; 95 \% \mathrm{CI}=-0.655$, -0.233 ) were less likely to exhibit HIV/AIDS-related discrimination toward PLWHA compared to non-Islam.

Data analysis from female respondents with the unstandardized regression coefficient $(\beta)$ with $95 \%$ confidence interval, adjusted $R^{2}=0.155, F(5,332)=11.172, p<0.001$ is also illustrated in Table 4 . The adjusted $R^{2}$ value 0.155 shows that $15.5 \%$ of the variability in HIV/AIDS-related discrimination toward PLWHA was predicted by a number of variables such as not knowing someone who had HIV, knowledge on HIV transmission and household income $(p<0.05)$. Apart from that, the analysis revealed that 'did not know someone who had HIV' had a significant positive contribution to HIV/ AIDS-related discrimination toward PLWHA. Furthermore, household income and knowledge on HIV transmission negatively influenced HIV/AIDS-related discrimination toward PLWHA. This indicated that those female respondents 'who did not know someone who had HIV' $(\beta=1.437$; $95 \% \mathrm{CI}=0.471,2.403$ ) were more likely to express HIV/AIDS- related discrimination toward PLWHA compared to those who knew someone who had HIV. However, those who had high knowledge on HIV transmission ( $\beta=-0.030$; 95\% $\mathrm{CI}=0.471,2.403$ ) were less likely to express HIV/AIDS-related discrimination toward PLWHA compared to those who had low knowledge on HIV transmission. Similarly, female respondents who had a household income more than MYR 1500 per month ( $\beta=-0.030 ; 95 \% \mathrm{CI}=-0.048,-0.013)$ were less likely to show HIV/AIDS-related discrimination toward PLWHA compared to those who had a household income not more than MYR 1500 per month. However, those female respondents who had a household income less than MYR 500 per month ( $\beta=-0.0207 ; 95 \% \mathrm{CI}=-0.381,-0.034)$ were less likely to exhibit HIV/AIDS-related discrimination toward PLWHA compared to those who had a household income more than MYR 500 per month. Moreover, the analysis revealed that 'did not know someone who had HIV' appeared to be a common factor in both genders and its percentage of contribution in the model was $8.2 \%$ for male respondents and $8.4 \%$ for female respondents. This indicated that those who 'did not know someone who had HIV' were more likely to express HIV/AIDS-related discrimination toward PLWHA.

\section{Discussion}

Our study found that the mean score of discrimination towards people with HIV/AIDS was higher among the female compared to the male respondents. This finding was consistent with previous studies [8, 20-23]. Wong [6] studied in Malaysia and argued that Malaysian awareness of HIV/ AIDS is lower among females compared to males, thus leading to a higher level of discriminatory attitude among females. However, a direct comparison between these studies and our study is not possible due to differences in measurement tools in other studies. Across all four domains of HIV/ 
AIDS-related discrimination, in general, respondents reported more discriminatory beliefs in the domain "physical and social isolation" than other domains. They had a high perceived discriminatory attitude towards PLWHA as they believed they should be isolated in a specialized healthcare institute and have labelled and separated PLWHA eating utensils. This finding was similar to previous studies [17]. An earlier study reported the belief that PLWHA should be isolated, i.e. $77.3 \%$ of the semi-urban community in Alor Gajah, Malaysia [24], $60 \%$ of the Malaysian adult community [6] and 21.2\% of the Tamil Nadu adult community [7] believed that HIV/ AIDS cases should be segregated from the community.

Ethnicity was also found as one of the predictors for a discriminatory attitude toward PLWHA among males. The current study found that males of Iban ethnicity expressed a less discriminatory attitude, but males of Malay ethnicity expressed a more discriminatory attitude toward PLWHA. This finding is similar to that of Wong [6], who mentioned that ethnicity is the strongest predictor of HIV/ AIDS-related discrimination. However, Wong and Syuha$\mathrm{da}$ [25] reported that ethnic Malays are more sympathetic or express less discrimination toward PLWHA. This might be due to Malays being more liberal and exhibiting the lowest level of discriminatory attitudes when it came to interaction with PLWHA [6]. However, other studies found no differences by ethnicity in attitudes toward PLWHA who are more educated and more aware of HIV/AIDS [10, 26].

Religion was one of the factors that influenced HIV/ AIDS-related discrimination toward PLWHA among males. Islamic male respondents expressed a less discriminatory attitude toward PLWHA compared to non-Islamic. This might be explained by the humble attitude and practice of forgiveness among the Muslim community [6]. In addition to that, religion can help people change behaviour in a positive way such as practical action on moral formation [27]. However, Zou et al. [28] reported the religious belief that HIV/AIDS is a punishment from God for their immoral behaviour.

Knowing someone with HIV was a strong predictor of HIV/AIDS-related discrimination toward PLWHA in both genders. It is reported that respondents who did not know PLWHA showed more discriminatory attitudes toward PLWHA compared to the respondents who claimed that they did know PLWHA. This finding was consistent with past studies [22, 29-31]. However, the finding contradicted Masoudnia [23], who found that respondents who did know PLWHA showed more discriminatory attitudes toward PLWHA compared to the respondents who claimed that they did not know PLWHA.

In our study, a lower score on "HIV/AIDS transmission knowledge" among female respondents contributed to high discrimination toward PLWHA. This finding is similar to other studies that found a negative relationship between awareness regarding HIV/AIDS and discriminatory attitude toward PLWHA [32-35]. This might be due to factors such as lack of correct knowledge on HIV/AIDS transmission and fear of contracting HIV/AIDS contributing to discrimination toward PLWHA [36]. Therefore, better knowledge on
HIV/AIDS transmission may be able to combat discrimination toward PLWHA. However, the finding from the current study contradicted Wong [6].

Household income also contributed a significant influence on HIV/AIDS-related discriminatory attitude towards PLWHA among female respondents. The current study showed that females who had a household income more than MYR 1500 per month expressed a less discriminatory attitude toward PLWHA, while females with household income of less than MYR 500 per month expressed a more discriminatory attitude toward PLWHA. Higher family income contributed to a less discriminatory attitude toward PLWHA. This might be due to respondents with a high family household income having received better quality education, indirectly leading to a lower level of discrimination toward PLWHA [37]. In contrast to the current study, previous studies indicated that lower family household income contributed to a less discriminatory attitude toward PLWHA [38].

Though this study tried to follow a rigorous sampling procedure, it had some limitations. This study focused on respondents' subjective attitudes and perception toward PLWHA. To conduct a more detailed study about discrimination, it would be better it the actual behaviour of people towards PLWHA were considered. Secondly, the data for this study were collected from the rural population; thus, extrapolation of the results to the urban population should be done with caution. Thirdly, there might be response bias as the respondents tended to give socially desired responses.

\section{Conclusions}

This study highlights the need for special attention to women in the community especially in Sarawak, as they expressed more discriminatory attitudes toward PLWHA compared to male respondents. Educational anti-stigma interventions aim to educate the community regarding HIV/ AIDS issues, hence improving their knowledge on HIV/ AIDS-related issues. Priority focus on females in the community and need collaboration with women society either government or NGOs. The strategies can be done through focus group discussion, and peer group discussion. Moreover, demographic, ethnicity, religion and socio-economic disparities have contributed more evidence suggesting the need for tailored socio-culturally accepted intervention.

\section{Acknowledgements}

We are very grateful to the Ketua Kampung (village headmen) for their support in selecting the houses and identification of respondents through the development of a sampling frame. We are also grateful to the research assistants who were involved in data collection. And finally, our gratitude goes to all the respondents who participated in this study. We are also grateful to Professor Dr Mohamad Taha Arif, Faculty of Medicine and Health Sciences, UNIMAS, for his manuscript editing and valuable comments. 


\section{Conflict of interest}

The authors declare no potential conflicts of interest with respect to the research, authorship, and/or publication of this article.

\section{References}

1. WHO. Global Health Observatory (GHO) data. Available at: http:// www.who.int/gho/hiv/en/.

2. Sarawak State Health Department. Sarawak Weekly Epid News [Internet]. State Health Department, Sarawak 2014; p. 1-311. Available at: www.jknsarawak.moh.gov.mylen/modules/wfdownload/visit.pdf.

3. $\mathrm{MOH}$, Malaysia. Malaysia UNGASS Country Progress Report 2010 [Internet]. Ministry of Health (Malaysia), Geneva 2010. Available from: http://ghdx.healthdata.org/record/malaysia-ungass-country-progress-report-2010 (Accessed: 7.05.2018).

4. UNAIDS. Reduction of HIV-related stigma and discrimination, 2014 [Internet]. Available at: http://www.unaids.org/en/resources/ documents/2014/ReductionofHIV-relatedstigmaanddiscrimination (Accessed: 4.06.2018).

5. Mahajan AP, Sayles JN, Patel VA, et al. Stigma in the HIV/AIDS epidemic: a review of the literature and recommendations for the way forward. AIDS Lond Engl 2008; 22 Suppl 2: S67-79.

6. Wong LP. Prevalence and Factors Associated with HIV/AIDS-Related Stigma and Discriminatory Attitudes: A Cross-Sectional Nationwide Study. Prev Med 2013; 57 Suppl: S60-63.

7. Chellan R, Rajendran P, Charles B, Ganeshan N. Perceived Stigma and Discrimination Towards People Living with HIV/AIDS among Young People in Tamil Nadu, India, 2012 [Internet]. Available at: http://epc2012.princeton.edu/papers/120043.

8. Oyediran K, Oladipo O, Anyanti J. HIV/AIDS Stigma and Discrimination in Nigeria, 2005 [Internet]. Available at: http://www.demoscope.ru/weekly/knigi/tours_2005/papers/iussp2005s51685.pdf.

9. Ekstrand ML, Ramakrishna J, Bharat S, Heylen E. Prevalence and drivers of HIV stigma among health providers in urban India: implications for interventions. J Int AIDS Soc 2013; 16 (3 Suppl 2): 18717.

10. Chew BH, Cheong AT. Assessing HIV/AIDS Knowledge and Stigmatizing Attitudes among Medical Students in Universiti Putra Malaysia. Med J Malaysia 2013; 68: 24-29.

11. Holzemer WL, Human S, Arudo J, et al. Exploring Hiv Stigma and Quality of Life for Persons Living with Hiv Infection. J Assoc Nurses AIDS Care JANAC 2009; 20: 161-168.

12. Young M, Stuber J, Ahern J, Galea S. Interpersonal discrimination and the health of illicit drug users. Am J Drug Alcohol Abuse 2005; 31: 371-391.

13. Pascoe EA, Smart Richman L. Perceived discrimination and health: a meta-analytic review. Psychol Bull 2009; 135: 531-554.

14. Suleiman A. Global AIDS Response Progress Report 2012 [Internet]. Ministry of Health, Malaysia, Kuala Lumpur 2012; p. 116. Available at: http://www.moh.gov.my/images/gallery/Report/GLOBAL_AIDS_Endorsed_DG.pdf.

15. Li L, Rotheram-Borus MJ, Lu Y, et al. Mass Media and HIV/AIDS in China. J Health Commun 2009; 14: 424-438.

16. Ragimana MA. Factors Related to the Stigma Associated with HIV/ AIDS in Attridgeville and Mamelodi [Internet] [Thesis]. University of Pretoria, South Africa 2006. Available at: https://repository. up.ac.za/bitstream/handle/2263/24213/dissertation.pdf;sequence=1

17. Ugarte WJ, Högberg U, Valladares EC, Essén B. Measuring HIV and AIDS Related Stigma and Discrimination in Nicaragua: Results from a Community-Based Study. AIDS Educ Prev Off Publ Int Soc AIDS Educ 2013; 25: 164-178.

18. UNAIDS. Reducing HIV Stigma and Discrimination a Critical Part of National AIDS Programmes: A Resource for National Stake- holders in the HIV Response. Joint United nations programme on HIV/AIDS (UNAIDS), Geneva 2007.

19. IBM SPSS. IBM SPSS Statistics for Windows. Armonk, New York, USA: IBM SPSS; 2013.

20. Amo-Adjei J, Darteh EKM. Drivers of Young People's Attitudes towards HIV/AIDS Stigma and Discrimination: Evidence from Ghana. Afr J Reprod Health 2013; 17: 51-59.

21. Chellan R, Charles B, Nanjan G, Periyathambi R. Perceived Stigma and Discrimination towards People Living With HIV/AIDS among Young People in Tamil Nadu, India. Int J Curr Res 2011; 3: 186-194.

22. Genberg BL, Hlavka Z, Konda KA, et al. A Comparison of HIV/ AIDS-Related Stigma in Four Countries: Negative Attitudes and Perceived Acts of Discrimination Towards People Living with HIV/ AIDS. Soc Sci Med 1982 2009; 68: 2279-2287.

23. Masoudnia E. Public perceptions about HIV/AIDS and discriminatory attitudes toward people living with acquired immunodeficiency syndrome in Iran. SAHARA J J Soc Asp HIVAIDS Res Alliance $2015 ; 12$ : 116-122.

24. Lugova H, Mon AA, Daher AM, Suleiman A. HIV-Related Stigma and Discriminatory Attitudes among a Semi-Urban Population. Malays J Med Sci MJMS 2015; 22: 64-69.

25. Wong LP, R Nur Syuhada A. Stigmatization and discrimination towards people living with or affected by HIV/AIDS by the general public in Malaysia. Southeast Asian J Trop Med Public Health 2011; 42: 1119-1129.

26. Rahnama R, Rampal L, Munn-Sann L, Rahman HA. Factors Influencing Students' Attitude towards HIV/AIDS in a Public University, Malaysia. Glob J Health Sci 2011; 3.

27. Deacon H, Stephney I, Prosalendis S. Understanding HIV/AIDS stigma: A theoretical and methodological analysis. HSRC Press, Cape Town 2005.

28. Zou J, Yamanaka Y, John M, et al. Religion and HIV in Tanzania: influence of religious beliefs on HIV stigma, disclosure, and treatment attitudes. BMC Public Health 2009; 9: 75.

29. Chiao C, Mishra V, Sambisa W. Individual- and community-level determinants of social acceptance of people living with HIV in Kenya: results from a national population-based survey. Health Place 2009; 15: 712-720.

30. Hutchinson PL, Mahlalela X. Utilization of Voluntary Counseling and Testing Services in the Eastern Cape, South Africa. AIDS Care 2006; 18: 446-455.

31. Visser MJ, Makin JD, Vandormael A, et al. HIV/AIDS stigma in a South African community. AIDS Care 2009; 21: 197-206.

32. Amuri M, Mitchell S, Cockcroft A, Andersson N. Socio-Economic Status and HIV/AIDS Stigma in Tanzania. AIDS Care 2011; 23: 378382.

33. Cao H, He N, Jiang Q, et al. Stigma against HIV-infected persons among migrant women living in Shanghai, China. AIDS Educ Prev 2010; 22: 445-454

34. Ouzouni C, Nakakis K. HIV/AIDS knowledge, attitudes and behaviours of student nurses. Health Sci J 2012; 6: 129-150.

35. Waite KR, Paasche-Orlow M, Rintamaki LS, et al. Literacy, Social Stigma, and HIV Medication Adherence. J Gen Intern Med 2008; 23: 1367-1372.

36. Thanavanh B, Harun-Or-Rashid M, Kasuya H, Sakamoto J. Knowledge, attitudes and practices regarding HIV/AIDS among male high school students in Lao People's Democratic Republic. J Int AIDS Soc 2013; 16: 17387.

37. Liu H, Li X, Stanton B, et al. Relation of Sexual Risks and Prevention Practices with Individuals' Stigmatising Beliefs Towards Hiv Infected Individuals: An Exploratory Study. Sex Transm Infect 2005; 81: 511-516.

38. Tee Y, Huang M. Knowledge of HIV/AIDS and attitudes towards people living with HIV among the general staff of a public university in Malaysia. SAHARA J J Soc Asp HIVAIDS Res Alliance 2009; 6: 179-187. 